\title{
Derecho del Consumo
}

\author{
Francisca Barrientos Camus
}

Profesora de Derecho Civil Universidad Diego Portales

Comentario. Ámbito de APlicación DE LA LEY N ${ }^{\circ} 19496$ DE 1997. NEgativa INJUSTIFICADA DE LA VENTA. OfERTA PROMOCIONAL. FORMACIÓN DEL CONSENTIMIENTO. COMPUTADORES PORTÁTILES A BAJO PRECIO. Buena FE DEL CONSUmidor. Tercera Sala Corte de ApeLaCiones de SANTIAGO, 12 de marzo DE 2012, ROL No 8470-2010 Y JUZGADO de Policía Local de Vitacura, 11 de NOVIEMBRE DE 2009, ROL No 114.876 .

Se trata de los computadores Dell y la oferta electrónica efectuada por el proveedor en su página web. El 24 de marzo de 2008 la empresa ofreció por medios electrónicos computadores portátiles modelo vostro 1500 a $\$ 31.000$, aproximadamente, que luego se negó a entregar alegando que la oferta no fue real o en subsidio la existencia de un error en el precio de la compraventa. Por esta razón el "consumidor" se querelló y demandó a la empresa proveedora exigiendo una indemnización de perjuicios y el cumplimiento de la oferta promocional (entrega de los tres notebook comprados).

En el caso que comento, el demandante fundó su acción en la aceptación de la oferta por medios electrónicos materializada en una serie de hechos. En efecto, el adquirente siguió todos los pasos del proceso de compra electrónica, adquirió los tres ordenadores al precio de $\$ 109.853$, los que fueron pagados mediante transferencia bancaria, luego, apareció la orden de compra con un número determinado y para finalizar recibió un correo de confirmación de la empresa que agradecía por la compra. Sobre la base de estos hechos denunció la infracción al artículo 13 de la de la LPDC, que prohíbe la negativa injustificada de la venta por parte de los proveedores en las condiciones ofrecidas.

Por su parte, la Tercera Sala de la Corte de Apelaciones de Santiago ratificó el fallo del Juzgado de Policía Local de Vitacura, que multó a la empresa con el pago de $\$ 200.000$ a beneficio fiscal por infracción al artículo 13 LPDC y ordenó la entrega de los tres computadores al confirmar la existencia de una oferta promocional, vinculante de su parte. Éste presenta una serie de problemas, como la modalidad de la contratación electrónica de la oferta 
y sus requisitos, el error en el precio de la compraventa, entre otros. Pese a la importancia de ellos, centraré mi comentario en dos temas que sirven de fundamento para una adecuada protección de los derechos de los consumidores. Se trata de dos puntos que no son esbozados por ninguno de los jueces que conocieron esta causa, pero que a mi juicio constituyen el punto de partida de todos los demás. Por una parte, la determinación del ámbito de aplicación de la LPDC y, por la otra, la buena fe del consumidor al momento de la contratación.

\section{I. Ámbito DE APLICACIÓN DE LA LPDC:}

CONFIGURACIÓN DE LA RELACIÓN
DE CONSUMO

Tal como se sugirió con anterioridad, hay un primer punto que es interesante analizar, cual es la existencia de la "relación de consumo" que en nuestro medio nacional se conoce como "ámbito de aplicación" de la LPDC. Y como es sabido para configurarlo se requiere la existencia de dos aspectos subjetivos y otro objetivo más controversial (la existencia de un acto mixto según la teoría del acto de comercio) ${ }^{1}$.

\footnotetext{
${ }^{1}$ No me pronunciaré sobre este requisito porque adhiero a la posición que le resta vigencia desde la entrada de la ley $\mathrm{N}^{\mathrm{o}} 19.955$ de reforma a la LPDC, cf. Rodrigo MOMBERG URIBE, "Ámbito de aplicación de la ley No 19.496 Sobre Protección de los Derechos de los Consumidores", en Revista Derecho, vol. No 17, Valdivia, 2004, pp. 41-62.
}

Desde el punto de vista subjetivo, la relación de consumo nace por la existencia de un proveedor (pasiva), y por la calificación del comprador o adquirente de la cosa o servicio de consumo masivo como consumidor (activa).

En este caso en particular no hay duda de que se configura la parte pasiva de la relación de consumo, ya que la empresa proveedora cumple a cabalidad con las condiciones impuestas en el artículo $1 \mathrm{~N}^{\mathrm{o}} 2$ de la LPDC, que define al proveedor como el empresario de bienes y servicios de consumo masivo.

Sin embargo, no es posible sostener lo mismo respecto de la parte activa. En efecto el querellante y demandante civil fue una persona en representación de Inversiones Comercial del Sol Limitada, que se individualizó como "empresario". Esto debería llamar la atención, ya que las relaciones de consumo se configuran por la existencia de un empresario y otro que no lo es -el consumidor-. Aquí, el sujeto activo es otra empresa proveedora que no cumple con la definición de consumidor.

Por este motivo, me parece que los tribunales extendieron la protección de esta ley a ámbitos que están más allá de la relación de consumo. Se otorgó el amparo de la ley protectora a una empresa frente a otra empresa en vez de someter este conflicto a las reglas propias de los comerciantes, el Código de Comercio.

Si se toma en consideración la definición de consumidor de la ley consagrada en el artículo $1 \mathrm{~N}^{\circ} 1$ es 
posible observar que se requiere ser "destinatario final" de los bienes y servicios, que ha sido explicado como el que no es "proveedor". Incluso, se ha comentado ${ }^{2}$, siguiendo a los españoles como Rodrigo Bercovitz-Rodríguez $\mathrm{Cano}^{3}$, que esta expresión sería sinónima de "consumidor final", es decir la persona que adquiere los bienes para utilizarlos el mismo.

En definitiva, el empresario no es consumidor. Así lo impone el artículo $1 \mathrm{~N}^{\mathrm{o}} 1$ parte final en términos que:

“[E]n ningún caso podrán ser considerados consumidores los que de acuerdo al número siguiente -definición de proveedores- deban entenderse como proveedores".

De ahí que siempre el consumidor deba ser el "destinatario final".

ésta es la esencia de la protección del consumidor, se ampara a una persona que no se encuentra en las mismas condiciones que el empresa-

${ }^{2}$ Rony Jara Amigo, "Ámbito de aplicación de la ley chilena de protección al consumidor: inclusiones y exclusiones", en Hernán Corral (edit.), Derecho del consumo y protección al consumidor. Estudios sobre la Ley $N^{0}$ 19.496 y las principales tendencias extranjeras, Cuadernos de Extensión Jurídica, $\mathrm{N}^{\circ}$ 3, Santiago, 1999, p. 54.

3 Alberto Bercovitz Rodríguez-Cano, "Ámbito de aplicación y derechos de los consumidores en la Ley General para la Defensa de los Consumidores y Usuarios", en Rodrigo Bercovitz y Alberto Bercovitz, Estudios jurídicos sobre protección de los consumidores, Madrid, Editorial Tecnos, 1987, p. 123. rio. Desde el punto de vista económico se diría que hay una asimetría en la información que perjudica a una de las parte del contrato. Éste es el fundamento de la legislación protectora. Por ello, no comparto la decisión de los tribunales de amparar al empresario bajo las reglas protectoras del consumo.

Con todo, pese a que es discutible, podría defenderse la posibilidad de que un empresario tenga la calidad de consumidor. En sentido favorable se ha pronunciado la doctrina nacional que ha estudiado el tema. Rodrigo Momberg ${ }^{4}$ estima que no puede descartarse definitivamente al empresario, profesional o comerciante como consumidor.

La jurisprudencia también ha admitido esta posibilidad, pero de forma restrictiva. Hay un fallo paradigmático que calificó como consumidor a un empresario. Es el Centro Veterinario Los Trapenses con Impresora y Comercial Publiguías S.A. ${ }^{5}$ en que la Corte Suprema consideró que la demandante tenía la calificación de consumidora respecto de los servicios de publicidad que contrató con la empresa proveedora. No estoy de acuerdo con ese argumento. Resulta difícil justificar que una empresa que lleva libros de contabilidad e inscribe ciertos documentos en el registro de comercio, que además tiene giro propio y tributa sobre la base de un régimen especial pueda

${ }^{4}$ Momberg Uribe (n. 1), p. 13.

${ }^{5}$ Corte Suprema, 18 de mayo de 2004, rol No 1421-2003, Legal Publishing $\mathrm{N}^{\circ} 30169$. 
ampararse en la protección pensada para otra clase de personas. No es ése el fin protector de esta normativa.

Me parece que es técnicamente más adecuado defender una posición restrictiva al respecto. Los empresarios no son consumidores, salvo quizá aquéllos que confunden ambas calidades como las PYMES, pero siempre como regulada como una excepción, por la dificultad que produce delimitar cuándo actúa como profesional o consumidor.

Ésa es la decisión legislativa que se mantiene en la actualidad. La ley $\mathrm{N}^{\mathrm{O}}$ 20.416 de 2010, que fija normas especiales para empresas de menor tamaño, permite que una "microempresa" 6 y una "pequeña empresa" tengan el papel de consumidoras y puedan ejercitar ciertos derechos de la LPDC, por ejemplo, la garantía legal. Con todo, se ha estimado que es una situación de excepción, pues la PYME mantiene la condición de empresa ${ }^{8}$ y sólo en determinados supuestos puede ejercer los derechos de los consumidores, porque la ley le ha otorgado la posibilidad. Me parece que la microempresa

${ }^{6}$ Son microempresas aquellas empresas cuyos ingresos anuales por ventas y servicios y otras actividades del giro no hayan superado las 2.400 UF en el último año calendario.

${ }^{7}$ Pequeñas empresas, aquéllas cuyos ingresos anuales por ventas, servicios y otras actividades del giro sean superiores a 2.400 UF y no exceden de $25.000 \mathrm{UF}$ en el último año calendario.

${ }^{8}$ Erika Isler Soto, "La relación de consumo como criterio de aplicabilidad del Derecho de protección del consumidor", en Revista de Derecho de la Empresa, No 23, Santiago, julio-septiembre, 2010, p. 111.

y pequeña empresa no se transforman en consumidores.

En definitiva, no se configuró la relación de consumo al no tener la calidad de consumidor el demandante. Esto quiere decir, que no correspondía aplicar las normas protectoras de la LPDC, ni la competencia y procedimiento de los juzgados de Policía Local. El empresario demandante debió iniciar un procedimiento ordinario bajo las reglas de los tribunales civiles.

La protección del consumidor se justifica para las personas naturales que cumplen con la condición de ser destinatarios finales de bienes y servicios de consumo masivo, lo que no ocurrió. También considero que las personas jurídicas que no tienen fines de lucro gozan del favor de la LPDC y por expresa disposición legal de forma excepcional se extiende esta protección a las personas jurídicas con fines de lucro como las microempresas y pequeñas empresas.

Dicho esto corresponde examinar la noción de buena fe para las partes contratantes especialmente del "consumidor”, sus alcances y límites.

\section{LA BUENA FE DEL CONSUMIDOR}

En este caso, el problema que enfrentó la Corte consistió en determinar si existía una oferta válida por parte del proveedor, tomando en consideración la aceptación del "consumidor".

Tal como se sostuvo con anterioridad, en este comentario dejo de lado el problema de la oferta y la contratación 
por medios electrónicos. Partiré de la base que, aun cuando es discutible, se configuró una oferta tal como lo sostuvo el Juzgado Policía Local y lo confirmó la Corte de Apelaciones. Hay un interesante estudio del profesor Iñigo de la $\mathrm{Maza}^{9}$, que examina un supuesto parecido -al menos de la misma empresa-y llega a la conclusión de que no existió una oferta seria efectuada por medios electrónicos (oferta sujeta a reserva). La diferencia con el caso que comento es que aquí hubo una confirmación y agradecimientos por la compra y en el otro no.

Lo que genera dudas -una vez reconocida la existencia de la oferta- es la posibilidad de que las empresas emprendan masivas campañas promocionales al rebajar sus precios, o sea, que formulen ofertas en el sentido del artículo $1 \mathrm{~N}^{\circ} 8 \mathrm{de}$ la LPDC y que luego se rehúsen a entregar los productos al invocar, por ejemplo, un error de cálculo ${ }^{10}$.

${ }^{9}$ Véase Iñigo de la Maza Gazmuri, "Ofertas sujetas reserva: a propósito de los términos y condiciones en los contratos celebrados por medios electrónicos", en Revista de Derecho, vol. XXII, No 2, Valdivia, 2009, pp. 75-95.

${ }^{10}$ Debo señalar que de los hechos descritos en el fallo no es posible deducir la existencia de una campaña promocional de los computadores a precios rebajados de forma transitoria, aun cuando la Corte entendió que éste era la norma aplicable. No hay indicios que den cuenta de un depósito de bases promocionales ni nada que indique que se trataba de una técnica de marketing. Por este motivo, llaman profundamente la atención los argumentos citados por la Corte de Apelaciones de Santiago para dirimir este conflicto.

La sentencia comentada invocó una serie de circunstancias sociológicas relacionadas
No es casualidad que la LPDC regule el cumplimiento forzado de estas ofertas en el artículo 53 inciso $2^{\circ}$.

Si se asume la existencia de una oferta que reúne todas las condiciones de validez (precisión y seriedad), queda luego por definir qué efectos produce la aceptación y qué papel representa la buena fe. Antes de eso, hay que volver a examinar algunas ideas planteadas al inicio de este comentario que tengan relación con el fin protector de esta legislación.

Como se ha dicho, la protección al consumidor se justifica, entre tantas razones, por la asimetría en la información que sufre el consumidor. Así se entiende que sea visto como

con la protección al consumidor para concluir que los computadores portátiles ofrecidos por la empresa a \$30.000 aproximadamente cada uno constituían una oferta (en el sentido del art. $1 \mathrm{~N}^{\circ} 8$ de la LPDC), que daba lugar a un precio real al ser "...una campaña de publicidad tal como acontece normalmente en el mundo del retail" (cons. $8^{\circ}$ ). La Tercera Sala de la Corte de Apelaciones de Santiago realizó una aplicación tópica para acudir a conceptos como la "equidad natural" o la "ausencia de ley" en la búsqueda de principios aplicables, incluso cita a un artículo del ex magistrado Rubén Galecio Gómez, Revista de Derecho y Jurisprudencia, tomo 63, Santiago, 1966, sección Derecho, p. 121), que transcribo: “...juzgar en un periodo en que los valores están alterados, el juez debe mirar con ojo vigilante en la conciencia pública y no ceder a la deformación de conceptos ético fundamentales y de los principios, y ha de formarse pues un juicio de deber ser sobre las conductas que juzgan y estar en situación de comprender los valores permanentes protegidos por la ley para compararlos con otros secundarios y accidentales, que también confluyen, a veces en oposición” (cons. $2^{\circ}$ ). 
la "parte débil del contrato". Sin embargo, esta noción ha quedado atrás al concebirlo como una persona "informada y razonable", que requiere protección de todas formas, pero tomando en consideración su nivel de información.

Se ha señalado con frecuencia que la legislación protectora no puede convertir a los consumidores en incapaces, pero también se reconoce que no todos los consumidores cuentan con la misma cantidad de información y que algunos de ellos están en mejores condiciones para procurárselas que, incluso, los mismos empresarios.

Es discutible que el consumidor electrónico sea la parte débil del contrato, porque sabe $-\mathrm{o}$, al menos, está 220 en condiciones de saber- los precios de los computadores. De este modo, es posible revisar el nivel de información que tenían las partes al momento de contratar y llegar a la conclusión de que el supuesto consumidor disponía de más información al adquirir los computadores al precio que aparecía en la página web. Lo que lleva a concluir que su actuación fue informada, pero no razonable lo que produjo una infracción en la confianza del empresario.

En este orden de ideas es posible acudir al principio general que inspira todo el ordenamiento jurídico incluido el ámbito de los consumidores, que rige la conducta de las partes y la contratación, cual es la buena fe. Interesa examinar la buena fe como regla de conducta del consumidor.

¿Podría un consumidor actuar de mala fe al efectuar la aceptar la oferta de computadores a un precio muy rebajado? ¿Qué hubiera pasado si el proveedor alegara la existencia de una conducta contraria a la buena fe del consumidor, como un abuso del derecho? ¿Condenarían los tribunales al consumidor bajo las normas que establecen una protección a su favor?

Veamos. En términos generales y sin pretender agotar el estudio del tema, es posible señalar que la tendencia de los tribunales en los casos Dell ha sido contraria a la que ahora comento, pero nunca se han impuesto multas o responsabilidad a los consumidores. Desde otra perspectiva, el organismo fiscalizador ha consolidado su política de "defender" a los consumidores incitando a exigir la entrega de los productos. Un año antes de los hechos relatados, el SERNAC establecía que no había "error" promoviendo la interposición de demandas colectivas por la oferta de computadores a tan sólo $\$ 8.000$ en el caso Wei Chile en junio de 2007.

La buena fe consiste en actitud buena (fides) que supone creencia y confianza $^{11}$. Jurídicamente se traduce en deber de conducta, y en una de sus manifestaciones opera como una causa de limitación del ejercicio de un derecho subjetivo o de cualquier otro poder jurídico ${ }^{12}$. Lo anterior se

${ }^{11}$ José Luis DE Los Mozos, El principio de la buena fe. Sus aplicaciones prácticas en el Derecho Civil español, Barcelona, Editorial Bosch, 1965, p. 27.

${ }^{12}$ Luis Díez Picazo, "Prólogo", en Franz Wieacker, Jose Luis Carro (trad.), El principio general de la buena fe, Madrid, Editorial Civitas, 1997, p. 19. 
puede relacionar con la doctrina del abuso del derecho que, pese a su difícil configuración técnica, supone un comportamiento ilegítimo del titular que no está amparado por el ordenamiento jurídico, que la sociedad no puede tolerar. Enrique Barros sugiere:

"[E]xisten casos en que el ejercicio de un derecho resulta contrario a la buena fe, porque supone extremar una facultad conferida por una norma hasta el límite de la deslealtad" ${ }^{\prime 3}$.

Esta idea podría aplicarse al caso particular y concluir que la desproporción se agrava aún más toda vez que es el consumidor electrónico es un sujeto más informado que sus pares que actúan en soporte de papel, y por este motivo tomaría una ventaja de su derecho legalmente amparado por la legislación protectora. Me parece que con estas conductas se vuelve a desequilibrar la posición de las partes, ahora en perjuicio del empresario.

Para complementar esta idea podría argumentarse que el consumidor infringió el deber de informarse de modo responsable de los bienes y servicios ofrecidos, su precio, condiciones de la contratación consagrado en el artículo 3 letra b de la LPDC.

En definitiva, no es necesario recordar que el consumo es un ámbito regulado de forma especial que se

${ }^{13}$ Enrique Barros Bourie, Tratado de responsabilidad extracontractual, Santiago, Editorial Jurídica de Chile, 2008, p. 633. caracteriza por la existencia de una parte débil que requiere el amparo de los jueces. Ello, en aras de equilibrar la posición de las partes en condiciones de igualdad y propender a una adecuada protección.

Por esta razón la aplicación de las normas de consumo no puede con llevar una sobreprotección o una protección que está más allá del ámbito de la propia ley. Por ello, la condescendencia hacia el consumidor -si es que existía tal- no alcanza a justificar esta decisión judicial.

\section{BibliogRAFÍA}

Barros Bourie, Enrique, Tratado de responsabilidad extracontractual, Santiago, Editorial Jurídica de Chile, 2008.

Bercovitz Rodríguez-Cano, Alberto, "Ámbito de aplicación y derechos de los consumidores en la Ley General para la Defensa de los Consumidores y Usuarios", en Rodrigo Bercovitz y Alberto BERCOviTz, Estudios jurídicos sobre protección de los consumidores, Madrid, Editorial Tecnos, 1987.

De la Maza Gazmuri, Iñigo, "Ofertas sujetas reserva: a propósito de los términos y condiciones en los contratos celebrados por medios electrónicos", en Revista de Derecho, vol. XXII, No 2, Valdivia, 2009.

De los Mozos, José Luis, El principio de la buena fe. Sus aplicaciones prácticas en el Derecho Civil español, Barcelona, Editorial Bosch, 1965.

Díez Picazo, Luis, "Prólogo", en Franz WieAcKer, Jose Luis Carro (trad.), El principio general de la buena fe, Madrid, Editorial Civitas, 1997. 
IsLER SOTo, Erika, "La relación de consumo como criterio de aplicabilidad del Derecho de protección del consumidor", en Revista de Derecho de la Empresa, $\mathrm{N}^{\mathrm{O}} 23$, Santiago, julioseptiembre, 2010.

Jara Amigo, Rony, "Ámbito de aplicación de la ley chilena de protección al consumidor: inclusiones y exclusiones”, en Hernán Corral (edit.),
Derecho del consumo y protección al consumidor. Estudios sobre la Ley $N^{o}$ 19.496 y las principales tendencias extranjeras, Cuadernos de Extensión Jurídica, No 3, Santiago, 1999.

Momberg Uribe, Rodrigo, “Ámbito de Aplicación de la Ley No 19.496 Sobre Protección de los Derechos de los Consumidores", en Revista Derecho, vol. No 17, Valdivia, 2004. 